\title{
An innovative concrete-steel structural system allowing for a fast and simple erection
}

\author{
C. Lepourry ${ }^{\mathrm{a}, \mathrm{b} *}$,H. Somja ${ }^{\mathrm{a}}$, P. Keo ${ }^{\mathrm{a}}$, P. Heng ${ }^{\mathrm{a}}$ and F. Palas ${ }^{\mathrm{b}}$ \\ ${ }^{a}$ National institute of applied sciences, Department of Civil Engineering, Rennes, France \\ ${ }^{\mathrm{b}}$ INGENOVA, Civil Engineering Office, Rennes, France \\ *corresponding author, e-mail address: clemence.lepourry@insa-rennes.fr
}

\begin{abstract}
In usual concrete buildings, medium to long span slabs can only be achieved by using prestressed beams. However, these elements are heavy, making their handling expensive; the cladding of these beams to vertical elements creates several difficulties, particularly in case of moment resisting frames; at last, their precamber implies a cautious management of the concreting and is a source of defects.

Steel-concrete composite beams may offer an alternative, with similar performances. However they are not considered by concrete builders, because specific tools and skills are needed to erect them on site. Moreover usual composite members require a supplementary fire protection, which is costly and unsightly.

This article presents an innovative steel-concrete moment resisting portal frame that overcomes these difficulties. It is based on composite tubular columns, and a composite beam made of a U-shaped steel profile used as permanent formwork to encase a concrete beam. This steel-concrete duality of beams allows an erection on site without any weld or bolt by a wise positioning of the construction joints. Moreover, as the resistance to fire is ensured by the concrete beam, the system does not require any additional fire protection. Finally, as only steel elements have to be handled on site, there is no need of heavy cranes. This system has been used to build a research center near Rennes, in France. As it is not covered in present norms, an experimental validation was required. After a detailed description of the structural system, the full-scale tests which have been performed are presented:

- A series of asymmetrical push-out tests in order to determine the behaviour and resistance of shear connectors;

- One 6-point bending test made to investigate the resistance of the USCHB under sagging bending moment;

Two tests of the beam-column joint.
\end{abstract}

Keywords: Hybrid steel-concrete beam; Innovative construction; $U$-shape steel profile; $L$ shape shear connector; beam-to-column joint; full-scale experimental test.

\section{Introduction}

In usual concrete buildings, medium to long span slabs can only be achieved by using prestressed beams. However, these elements are heavy, making their handling expensive; the cladding of these beams to vertical elements creates several difficulties, particularly in case of moment resisting frames; at last, their precamber implies a cautious management of the concreting and is a source of defects.

Steel-concrete composite beams may offer an alternative, with similar performances.
However, they are not considered by concrete builders, because specific tools and skills are needed to erect them on site and make connections between members. Moreover, usual composite members require a supplementary fire protection, which is costly and unsightly.

This article presents an innovative steelconcrete moment resisting portal frame that overcomes these difficulties. It is based on composite tubular columns, and composite beams made of a U-shaped steel profile used as permanent formwork to encase a concrete beam, 
named U-shaped steel-concrete hybrid beam (USCHB), see Fig.1.

U-shaped steel girders with concrete infill have already been proposed in the past, for example by Liu et al [1]. The objective was then to overcome the maximum span of traditional composite members made with an I-shaped steel girder, which was limited by local instabilities and lateral-torsional buckling. A shortcoming of this solution is the fact that no reinforcement rebars are added in the concrete beam drop leading to its inefficiency. In the actual USCHB, the concrete beam drop is reinforced. Thus, the beam is dual it is a composite beam as well as a concrete beam, and the infill contributes to increase both the flexural and shear resistance of the composite beam.

As a consequence, the resistance to fire can be ensured by the inside concrete beam, and the system does not require any additional fire protection. This advantage is not detailed in present article.

The duality of the beam is also used to make the solution adapted to concrete builders. A wise positioning of the construction joints at inflection points of the bending moment diagram in the beam allows an erection on site without any weld or bolt, as the connection can be made only by the continuity of the concrete beam, see Fig. 1. As a consequence, the steel portal frame is divided in three elements prefabricated in the factory: the central part of the beam, and the two columns welded to the hogging of the beam.

As already pointed out in general for composite beams, there is no need of heavy cranes on site as only steel elements have to be handled.

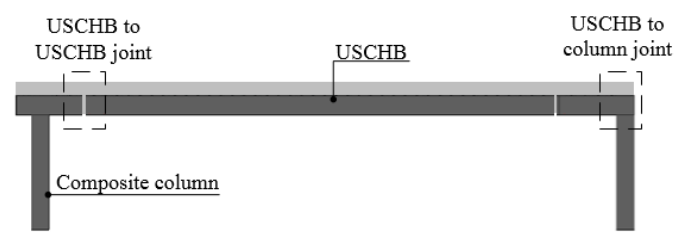

Fig. 1. The hybrid portal frame

This last point was decisive in the choice of the hybrid portal frame for its first application: the construction of the AVRIL headquarters in Rennes, France (Fig. 2). This building is a circular ring with an external circumference of $80 \mathrm{~m}$. It is three storey high, and the structural skeleton is composed of $9015-\mathrm{m}$ span hybrid frames.

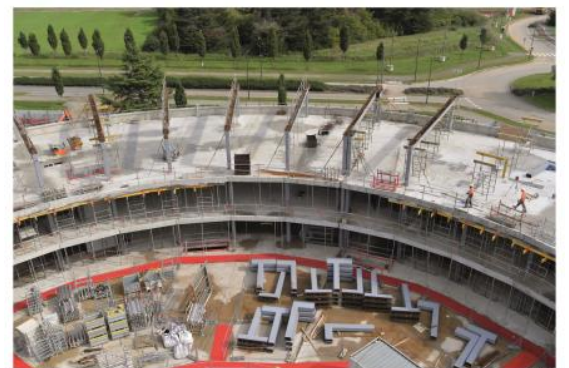

Fig. 2. Picture of the AVRIL construction site

The paper presents both the design of the different components of the portal frame, and its experimental validation. At first, the resistance and behavior of the UCSHB under positive bending moment, including the characterization of the specific steel-concrete shear connection, is detailed. Then, the global structural analysis that was performed is presented. After this, concept of the connection at inflection point are shown. Finally, the hybrid steel-column joint and its experimental validation are explained, as well as the connections of the column feet.

\section{USCHB in positive bending moment}

\subsection{Description of USCHB}

USCHB is composed of a U-shaped steel profile, a slab deck, an infill concrete element and shears connectors see Fig. 3 and Fig. 4. On AVRIL project, the U-shaped steel profile is a cold-formed steel plate with a thickness of $6 \mathrm{~mm}$. The lower flange is $300 \mathrm{~mm}$ wide, webs are 500 $\mathrm{mm}$ high, and upper flanges are $100 \mathrm{~mm}$ wide. The latter are used as supports for precast concrete slabs. Composite mechanism of USCHB is ensured by shear connectors. Headed shear stud connectors are usually chosen in many composite beams [2,3], but not suitable for USCHB due to the small thickness of the Ushape steel profile. L-angle shear connectors welded to the two upper edges of the U-shape steel profile (Fig. 3) are then adopted.

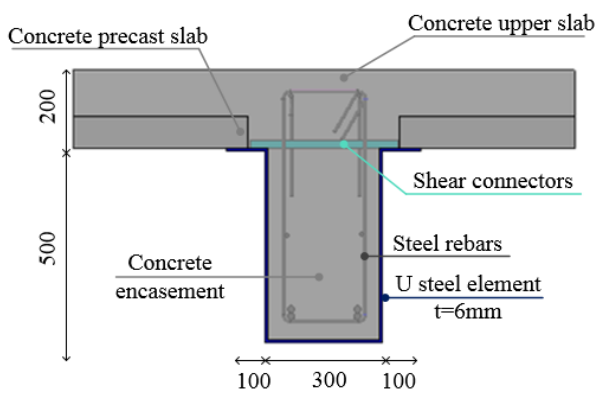

Fig. 3. USCHB Cross-section 
In the first part of this section, a series of large-scale push-out tests is performed in order to determine the characteristics of this new type of shear connectors. Then, a 6-point bending moment test is performed to check if stiffnesses and resistances of the composite and concrete beams can be added.

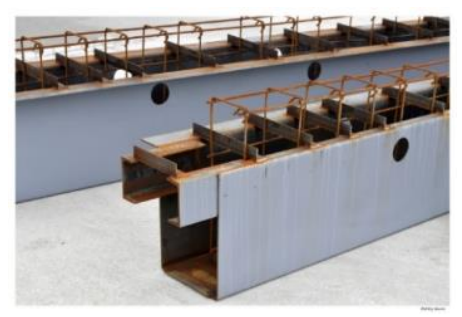

Fig. 4. U Shaped Concrete-Steel Hybrid Beam

\subsection{Push-out test on shear connectors}

Four asymmetrical push-out tests have been performed, see Fig. 5, inspiring from tests presented by Chinn [2] and Lowe et al.[3]. They have been described in a previous article [4].

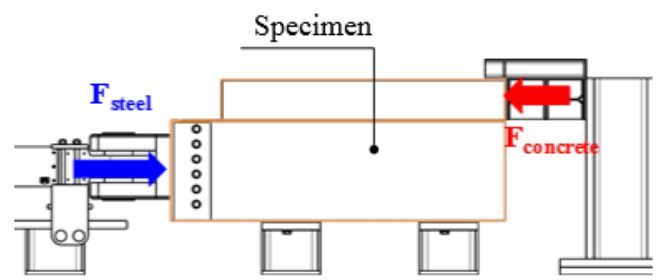

Fig. 5. Push-out test setup

In the first specimen, the steel-concrete connection is achieved by 3 angles with dimensions of $40 \times 40 \times 4 \mathrm{~mm}$ and is denoted "L 40 ". The other three specimens, denoted "L50-I"," $\mathrm{L}_{50-\mathrm{II}}$ " and " $\mathrm{L}_{50-\mathrm{III}}$ " use 3 angles with dimensions of 50x50x5 mm. The length of the specimen is $1200 \mathrm{~mm}$. The cast-in-place concrete block and the precast concrete slab are made of $C 25 / 30$ and $C 40 / 45$ respectively. The steel grades of U-shaped steel beam, and of Lshaped shear connectors are S355 and S235, respectively. Surfaces between the U-shaped steel profile and the concrete block are greased in order to distribute shear forces exclusively to the shear connectors.

Recommendations of Eurocode 4 [5] were followed to define the loading procedure. The test was made at an early age of the concrete in order to get a concrete resistance between 60 and $80 \%$ of the characteristic value. 25 loading/unloading cycles between 5 and $40 \%$ of the ultimate load were applied before loading up to failure.
The force-slip curve for one shear connector is illustrated in Fig. 6. The maximum load and the ultimate slip have been computed following EC4 [5], and are reported in Table 1. As ultimate slips are higher than $6 \mathrm{~mm}$, L-section shear connectors can be considered as ductile following Eurocode 4 [5].

Table 1 : Results for push-out test

\begin{tabular}{ccccc}
\hline & $\mathbf{L}_{\mathbf{4 0}}$ & $\mathbf{L}_{50-I}$ & $\mathbf{L}_{50-\text { II }}$ & $\mathbf{L}_{50-1 I I}$ \\
\hline $\mathrm{P}_{\max }(\mathrm{kN})$ & 212 & 310 & 305 & 325 \\
\hline$\delta_{\mathrm{u}}(\mathrm{mm})$ & 8.22 & 14.22 & 8.63 & 17.44 \\
\hline
\end{tabular}

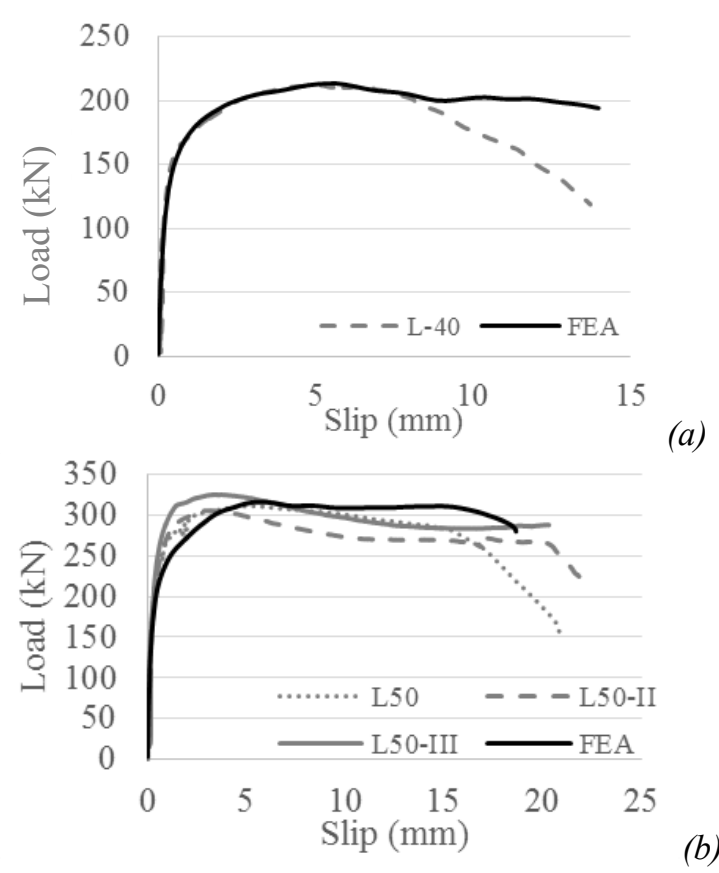

Fig. 6. Force-slip curve by connector: $\mathrm{L}_{40}$ (a) and $\mathrm{L}_{50}$ (b)

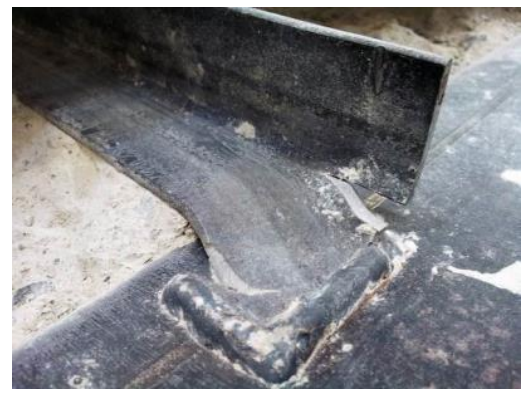

Fig. 7. Angle deformations after testing

During experimental testing, no cracks were observed on the concrete slabs. After testing the concrete was removed to examine the connectors as seen in Fig. 7. The plastic deformations of shear connectors are located near the zones welded to the upper flanges. 
Numerical simulations made with Abaqus were able to reproduce the experimental behavior [4]. This computation confirmed that the ultimate load was fixed by the shear yielding of the steel angle, see Fig. 8.

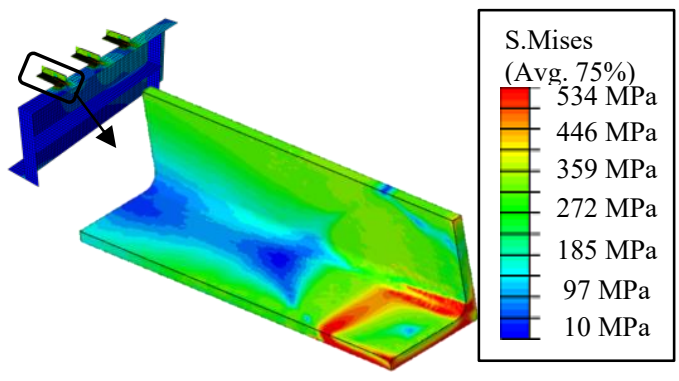

Fig. 8. Yielding of the steel angle at collapse

As a consequence, the following design formula has been proposed:

$P_{u}=2\left(A_{s 1}+A_{s 2}\right) \frac{f_{u}}{\sqrt{3}}+2 K_{c} A_{c} f_{c}$

with $A_{s 1}$ and $A_{s 2}$, the areas of the steel angle submitted to plastic shear at collapse, see Fig. 9, $f_{u}$ the ultimate stress of steel, $A_{c}$, the steelconcrete contact area of the part of the angle still connected to the U-shaped steel profile at collapse, $f_{c}$ the resistance of concrete in compression, and $\mathrm{K}_{\mathrm{c}}$ given by the following equation :

$K_{c}=19-38 \frac{h_{a}}{H_{c}}$

with $h_{a}$ the height of the angle, $H_{c}$ the height of the concrete slab.

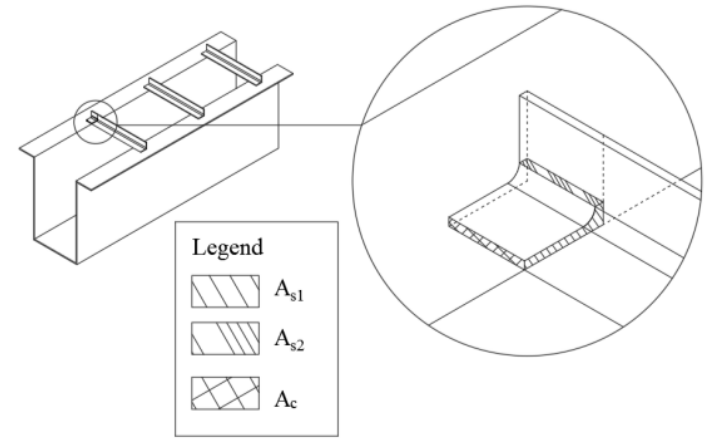

Fig. 9. Shear plans and concrete-steel contact plan

\subsection{6-point bending moment experimental test}

The cross section of the specimen is the one defined in Fig. 3, with a width of the slab of $2500 \mathrm{~mm}$. The length of the specimen is $10600 \mathrm{~mm}$. Shear connectors with dimensions of $50 \times 50 \times 5 \mathrm{~mm}$ are used with a spacing of $300 \mathrm{~mm}$. Material properties are the same as the ones used in the push-out test. Inside tensile rebars are 4HA16 as seen in Fig. 16.

The specimen is simply supported, as illustrated in Fig. 10. The load is applied by a hydraulic jack on a system of spreader beams to obtain a 4-point loading.

The force-displacement at mid span curve is presented in Fig. 11, and compared to a numerical simulation made with the FEA HBCOL software [6], that takes into account the nonlinearities of the steel and concrete, as well as the one of the steel-concrete connection. As can be seen, the comparison is very good. The picture of the specimen, Fig. 12, shows the large ductility of the USCHB.

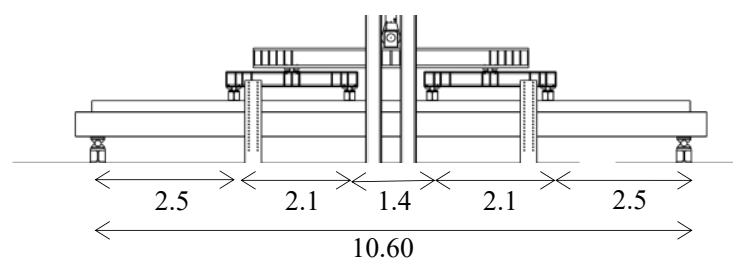

Fig. 10. 6-point bending moment test setup (dimensions in $\mathrm{m}$ )

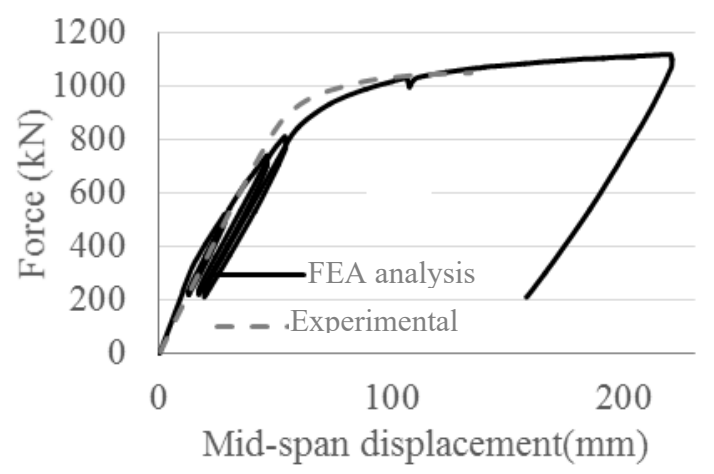

Fig. 11. Force-displacement curve at mid span

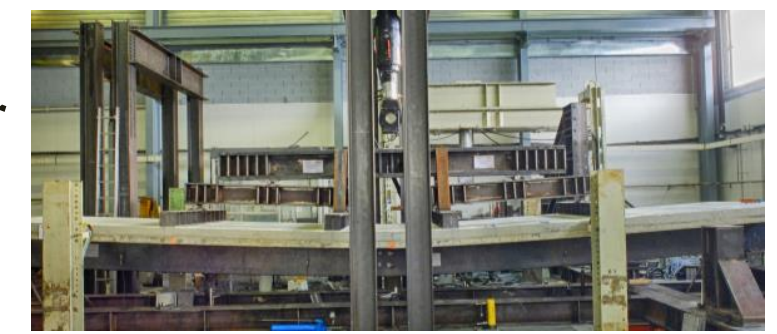

Fig. 12. Deflection of the beam after test

Supposing that the Bernoulli hypothesis is applicable, the moment-curvature curve can be drawn based on material laws and section properties. It can be seen from Fig. 13 that the experimental curve fits well with the theoretical one. Ultimate bending moment obtained from the experiment is $1921 \mathrm{kNm}$ whereas the one 
obtained from analytical computation is 1865 $\mathrm{kNm}$.

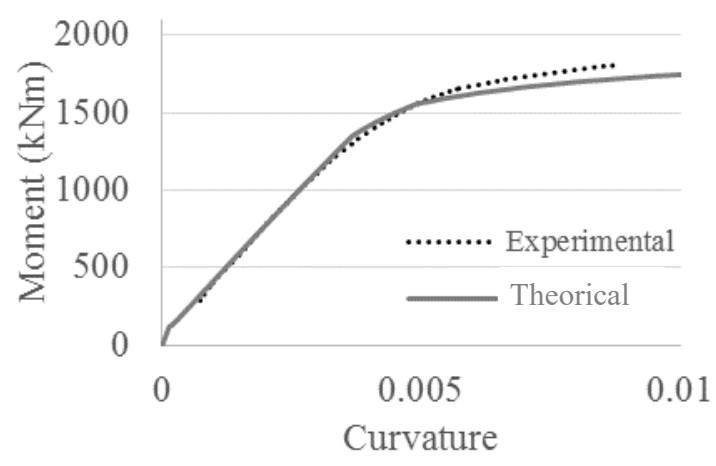

Fig. 13. Moment-curvature curve at mid span

It can be concluded that the behaviour of the USCHB under hogging bending moment can be determined using the formulation adopting the hypothesis of plane section.

\section{Structural analysis of the portal frame}

The software HBCOL developed initially by Keo [6] for the study of hybrid members has been extended to handle portal frames. It is based on a plane beam finite element written in corotational description and is able to take into account geometrical and material nonlinearities, as well as the effects of partial shear connection. The stress-strain relationships for steel rebars, steel and concrete are chosen following the recommendations of Eurocode 4 [5]. For shear connectors, the stress-strain relationship is based on test results.

The fiber approach makes possible the division of the bending moments between the steel and the concrete parts of the section. The shear force supported by each material is then deduced by the derivation of the bending moments. This allows to design the stirrups in the concrete beam. Bending moment diagram at ULS is given in Fig. 14 and displacements at SLS in Fig. 15. The resulting sections are presented in Fig. 16.

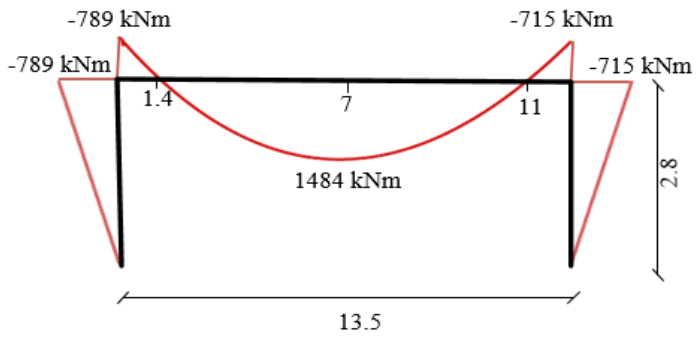

Fig. 14. Maximum bending moments at ULS (position in $\mathrm{m}$ )

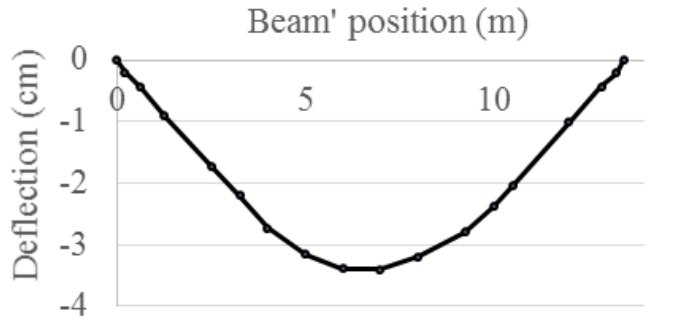

Fig. 15. Deflections at SLS
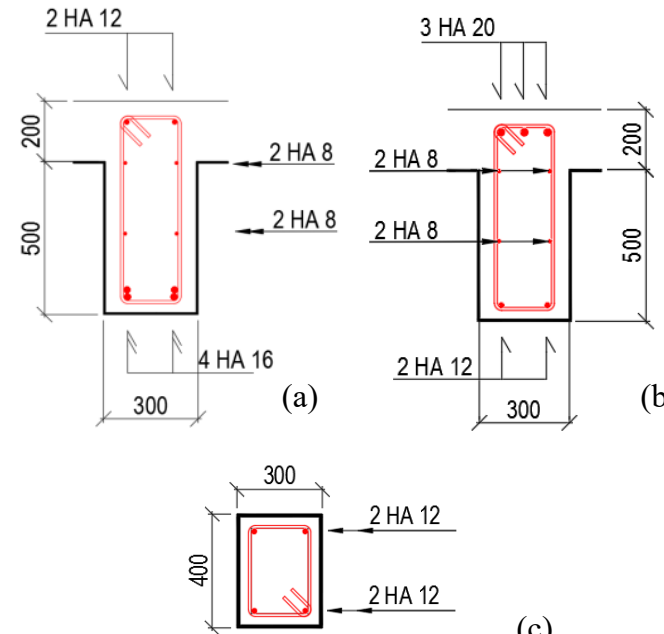

(c)

Fig. 16. Cross section and rebars of UCSHB

in sagging (a) and hogging zone (b), and column (c)

\section{USCHB to USCHB connection}

As already explained in the introduction, the steel part of the portal frame is prefabricated in three parts that are assembled on site by the casting of the concrete, without any bolt or weld. The steel discontinuity is located in the beam, near the inflexion point of the bending moment diagram under permanent loads, see Fig. 1.

The central part is called "beam A" and the outer part of the beam "beam B". The extremities of beam A and beam B are presented in Fig. 17 and Fig. 18 respectively.

In order to get the actions on the joint, nonlinear structural analyses of portal frame have been cautiously extended by a large parametrical study, taking into account the effect of variable loads, possible geometrical imperfections, effects of an eventual settlement and of a possible flexibility of the beam-column joint. The envelop of bending moments and shear forces supported by each material have then been deduced. Moreover they have been 
multiplied by a factor equal to 1.4 to make this critical zone over-resistant.

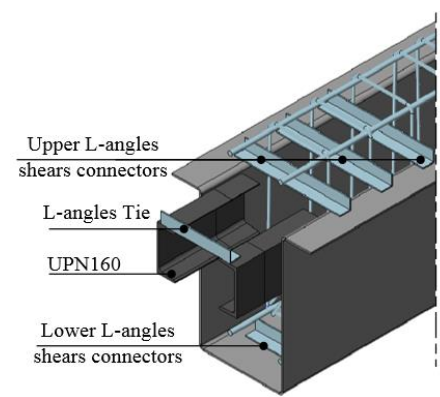

Fig. 17. Detailing - end of beam A

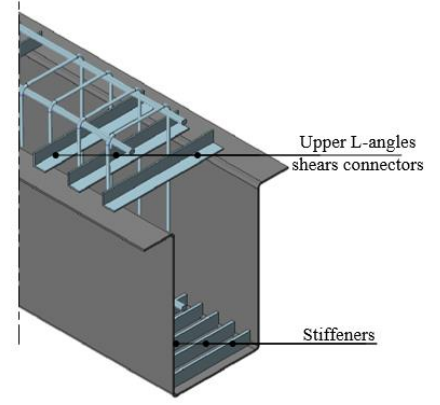

Fig. 18. Detailing - end of beam B

The transfer of steel shear forces from beam A to the steel section of beam B is made from the 2 protruding UPN profiles welded on the webs of beam $A$ to the stiffeners welded on the bottom flange of beam B by the concrete. The strut and tie model considered for the design is illustrated in Fig. 19.

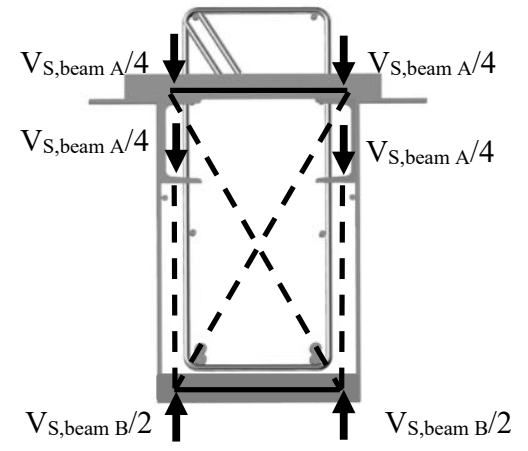

Fig. 19. Strut and tie model of inflexion point

The transfer in concrete beam of longitudinal forces existing in upper and lower flanges of the U-shaped section is ensured by additional Langle shear connectors or stiffeners welded on flanges on both sides of the joint. The additional tension transmitted in the concrete is resisted by two additional reinforcing cages overlapping the joint, see Fig. 20.

Whereas all the components can be designed using Eurocodes $[5,7,8]$, the USCHB to
USCHB joint has been validated experimentally under sagging and hogging moments.

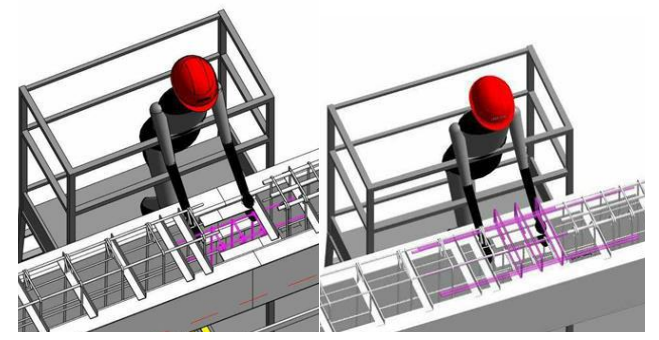

Fig. 20. Additional cages at inflexion point

\section{USCHB to column connection}

\subsection{Design}

Whereas the USCHB is a hybrid section, in which bending moments in steel and in concrete have the same order of magnitude, in the composite column the resistance is mainly provided by the steel cross-section. As a consequence, the beam-column joint is the superposition of three joints:

- A rather usual concrete to concrete joint, that transfers a minor part of the moment;

- An also usual welded steel beam to column joint, where the equilibrium of horizontal and vertical compression and tension forces generated by bending moments in the beam and in the column is obtained by shear in the web panels, see Fig. 21 (a);

- An original concrete beam to steel column joint, where the transmission of forces from concrete to steel must be ensured by means of connectors, see Fig. 21 (b).

The steel to steel joint is ensured by letting the steel column go through the U-shaped cross section up to the upper flange, see Fig. 22 (a). Then webs are fixed together by a peripheral welding, so that both webs participate in the shear panel.

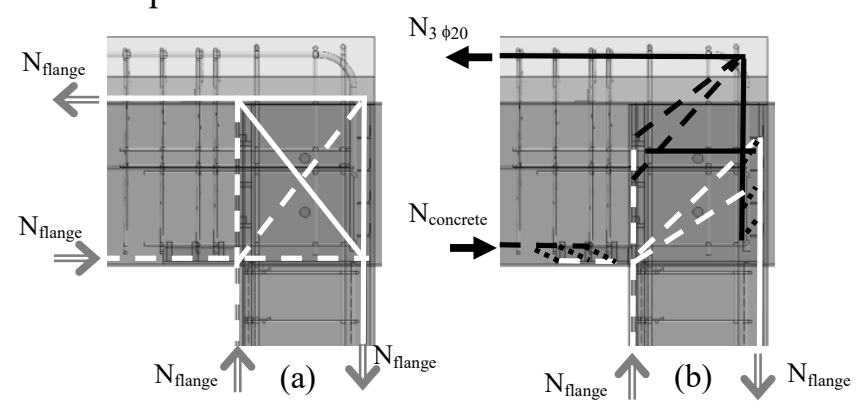

Fig. 21. Main strut and tie model for steel-to steel (a) and concrete to steel joints (b)

For the concrete beam to column joint, the strut and tie model is presented Fig. 21 (b). First, 
a V-shape hole is cut in the inner flange of the column to allow continuity of concrete strut in compression. Then, connectors are welded to the lower flange of the USCHB in order to transmit a part of the compression force from concrete to steel. The horizontal top rebars $(3 \varnothing 20)$, as seen Fig. 22 (b), are folded at right angle but their vertical part is only $500 \mathrm{~mm}$ long. This is indeed enough to transmit the tension force of the outer flange of the column to these bars through 4 angles.

As both vertical and horizontal parts of the $\varnothing 20$ rebars are in tension, a diagonal strut is anchored in the hook of the rebars. At their other end, diagonal struts are equilibrated partly in the concrete, but mostly by transversal stiffeners welded on the inner flange of the column.

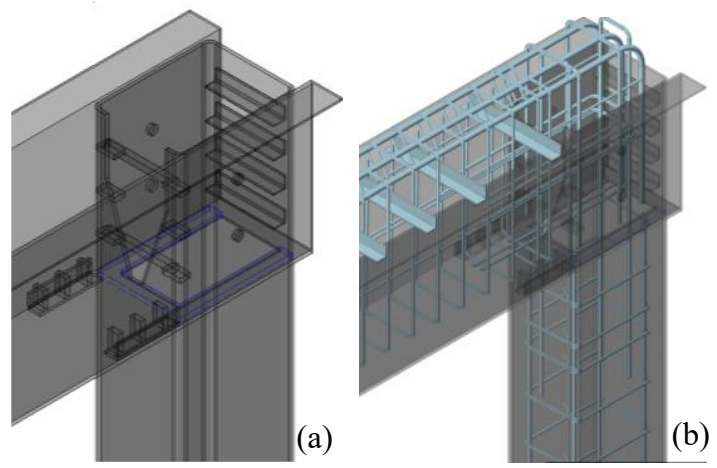

Fig. 22. Details of the hybrid joint: with steel reinforcement (a) and with steel rebars (b)

\subsection{Experimental validation}

Given the unusual aspect of this joint, experimental validation was mandatory. Two large-scale experimental tests have been performed. The test specimen is made of the composite column and the hogging zone of the USCHB beam. The dimensions of the crosssections of these members are given in Fig. 3 and Fig. 16. The lengths of column and beam are $2.845 \mathrm{~m}$ and $1.5 \mathrm{~m}$, respectively. The width of the concrete slab is $1100 \mathrm{~mm}$.

The configuration of the test setup is illustrated in Fig. 23. The specimen is rotated by 90 degrees. A horizontal load is applied at the end of the USCHB through a hydraulic jack in order to produce the hogging bending moment. The supports at the column base and at the end of USCHB are hinged.

The moment-rotation curve is given Fig. 23, and a photo of the specimen after test in Fig. 24. As can be seen, a very large ductility is obtained. The failure of the specimen is governed by the plastic buckling of the column's lower flange. The maximum bending moments of the tests are $1258 \mathrm{kNm}$ and $1235 \mathrm{kNm}$, respectively. These maximum moments are 1.5 times larger than the design bending moment.

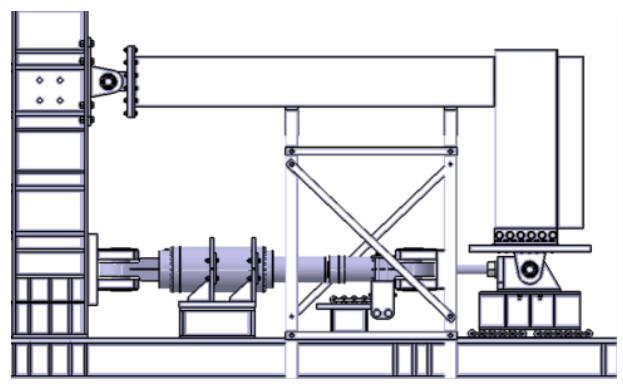

Fig. 23. Test setup for the hybrid joint

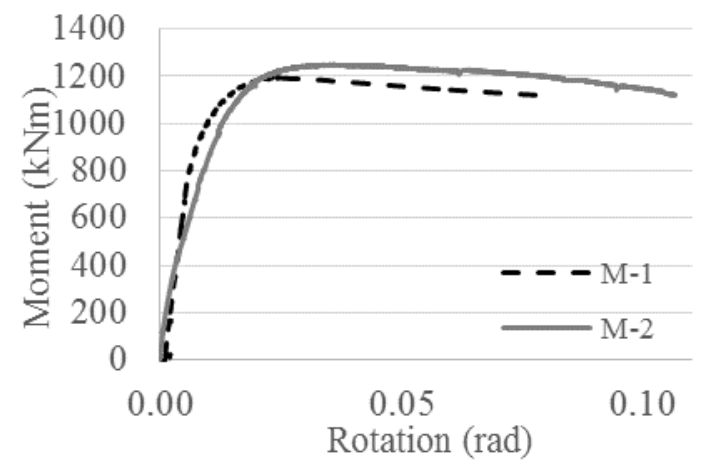

Fig. 24. Rotation-bending moment diagram

The initial stiffness of the joint is lower than the limit given in EN 1993-1-8 [7] to consider it as rigid. As a consequence, its stiffness must be taken into account in the global structural analysis. However, the maximal deflection at frame mid span is changed by only $5 \%$.

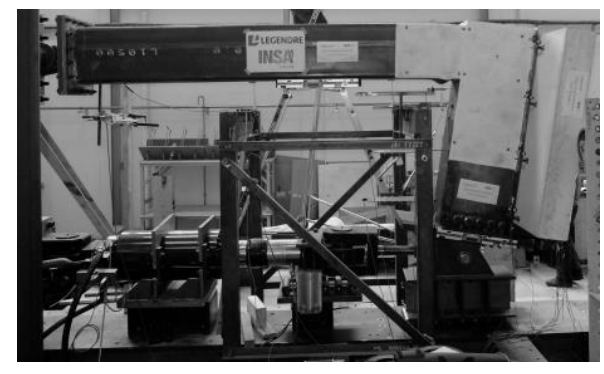

Fig. 25. Beam-column joint after collapse

\section{Column base joint}

The connection at column base also has to be fast and easy, without any bolts or welds. The joint at column base is conceptualized to work as a hinge. This is achieved by welding four Langles, each at one side of the column (Fig. 26). After casting, these L-angles transfer the stresses from the steel to the infilled concrete member so 
that the hinged connection is made only by the inside concrete column.
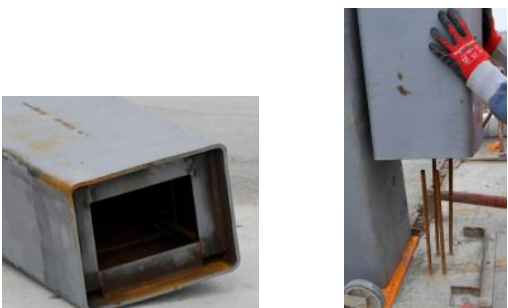

Fig. 26. Column shoe connection

\section{Feedback of the on-site erection}

The AVRIL building is the first project where USCHB were set up. Erection's steps were as follows:

1. Place the 3 steel elements on props. The positioning was extremely precise, and no difficulties arose in this phase.

2. Cast the columns and the inside of the Ushaped steel profile with a self-compacting concrete.

3. Place the precast slab.

4. Cast the slab.

As the system was considered to save time on site, the feedback of workers was of primary importance. They enjoyed the USCHB, as steel elements are easier to handle than prestressed members. As a consequence, the assembly is fast and secure. These new elements have increased the set up throughput.

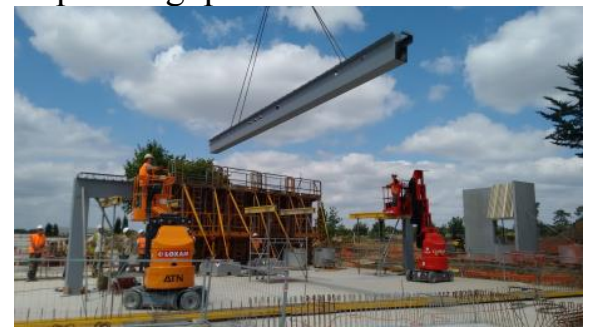

Fig. 27. Erection of the steel portal frame

\section{Conclusions}

On the basis of a U-shaped steel profile used as permanent formwork, an innovative concretesteel hybrid beam has been developed. The Ushaped steel profile acts as a composite beam with the slab, while the infill concrete acts as a classical concrete beam. This system is able to reach spans similar to the ones of prestressed members, while being lighter and easier to set up.

This system is the basis of a hybrid portal frame that was used on a pilot project, the
AVRIL R\&D center near Rennes. It was taken advantage of the duality of the UCSHB to make the on site joints only for the concrete beam, allowing an assembly without any weld or bolt on site.

The design procedure of the members and of the joints has been validated by experimental tests, and has obtained an approval from the CSTB, the French certification organism. First feedback of this new solution were good, workers enjoy the quick assembly and the increase of security on site.

Acknowledgements. The authors gratefully acknowledge financial support by the ANR (Agence Nationale de la Recherche, France) through the project LabCom ANR B-HYBRID.

\section{References}

[1] Liu Y, Guo L, Qu B, Zhang S. Experimental investigation on the flexural behavior of steel-concrete composite beams with Ushaped steel girders and angle connectors. Engineering Structures 2017; 131:492-502.

[2] Chinn J. Pushout Tests on Lightweight Composite Slabs. AISC Engineering Journal 1965, 2(4) 129-134

[3] Lowe D, Das R, Clifton C. Characterization of the Splitting Behavior of Steel-concrete Composite Beams with Shear Stud Connection. Procedia Mater Sci 2014; 3:2174-2179.

[4] Keo P, Lepourry C, Somja H, Palas F. Behavior of a New Type of Shear Connector for U-Shaped Steel-Concrete Hybrid Beams. Proceedings of the 2017 fib Symposium 2017; 1344-1352.

[5] CEN. Eurocode 4: EN 1994-1-1 Design of composite steel and concrete structures, Part 1.1- General Rules for buildings. Brussels 2004.

[6] Keo P, Somja H, Nguyen QH and Hjiaj M. Simplified design method for slender hybrid columns. Journal of Constructional Steel Research 2015; 110:101-120

[7] CEN. Eurocode 2: EN 1992-1-1 Design of concrete structures, Part 1.1 - General Rules for buildings. Brussels; 2004

[8] CEN. Eurocode 3: Design of steel structures -Part 1-1: General rules and rules for buildings (NF EN 1993-1-1). Brussels; 2004. 